\title{
Cellular Localization of the Prohormone Convertases in the Hypothalamic Paraventricular and Supraoptic Nuclei: Selective Regulation of PC1 in Corticotrophin-Releasing Hormone Parvocellular Neurons Mediated by Glucocorticoids
}

\author{
Weijia Dong, Bertolt Seidel, Mieczyslaw Marcinkiewicz, Michel Chrétien, Nabil G. Seidah, and Robert Day \\ J. A. DeSève Laboratory of Biochemical Neuroendocrinology, Clinical Research Institute of Montréal, Montréal, Québec, \\ Canada H2W $1 R 7$
}

The prohormone convertases (PCs) are processing enzymes that activate proproteins via cleavage at specific single or pairs of basic residues. The hypothalamic paraventricular nucleus (PVN) and supraoptic nucleus (SON) are primary sites of biosynthesis of several neuroendocrine hormone precursors, including provasopressin (pro-AVP), pro-oxytocin (pro-OT), and procorticotrophin-releasing hormone (pro- $\mathrm{CRH}$ ), which require post-translational processing to yield active products. Using in situ hybridization, we observed PC1 and PC5 mRNAs in PVN and SON magnocellular neurons, while PC2 mRNA was observed in both magnocellular and parvocellular PVN neurons as well as magnocellular SON neurons. Similar to furin, PC7 mRNA was expressed throughout the PVN and SON, whereas PACE4 mRNA levels were undetectable. Both immunohistochemical and Western blot studies were performed to demonstrate the presence of PC proteins and forms in the PVN and SON. Using double-labeling in situ hybridization, we examined the cellular colocalization of each PC mRNA with pro-AVP, pro-OT, and pro-CRH mRNAs in PVN and SON. PC1 mRNA was colocalized with both AVP and OT mRNA in PVN and SON magnocellular neurons. All AVP, OT, and $\mathrm{CRH}$ neurons expressed PC2. In contrast, PC5 mRNA was colocalized only with OT mRNA. We examined the effects of adrenalectomy (ADX) on PVN PC mRNA levels. PC1 mRNA levels were increased selectively within $\mathrm{CRH} / \mathrm{AVP}$ parvocellular neurons but were unchanged in PVN magnocellular AVP or OT neurons. These results established the anatomical organization of each convertase and proneuropeptide substrates in the PVN and SON and suggested potential roles for each enzyme under resting and stimulated conditions.

Key words: in situ hybridization; processing; neuropeptides; hypothalamic-pituitary-adrenal axis; proprotein convertases; immunohistochemistry
Regulatory neuropeptides initially are synthesized as biologically inactive protein precursors that require endoproteolytic cleavage at the C-terminal side of specific single or pairs of basic residues (e.g., Arg $\downarrow$ or Lys-Arg $\downarrow$ ) as the first step for activation. Post-translational processing is performed by a family of subtilisin/kexin-like enzymes known as the prohormone convertases (PCs). These include furin (Roebroek et al., 1986; Van de Ven et al., 1990), also named PACE (Barr et al., 1991); PC1 (Seidah et al., 1990, 1991), also named PC3 (Smeekens et al., 1991); PC2 (Seidah et al., 1990; Smeekens and Steiner, 1990); PC4 (Nakayama et al., 1992; Seidah et al., 1992); PACE4 (Kiefer et al., 1991); and PC5 (Lusson et al., 1993), also named PC6 (Nakagawa et al., 1993). Recently, a new PC was discovered and named PC7 (Seidah et al., 1996), also named PC8 (Bruzzaniti et al., 1996) and LPC (Meerabux et al., 1996).

Our previous studies demonstrated that each PC is expressed distinctly in the rat CNS (Day et al., 1993; Schäfer et al., 1993; Dong et al., 1995; Seidah et al., 1996) with the exception of PC4

Received May 29, 1996; revised Oct. 7, 1996; accepted Oct. 24, 1996.

This work was supported by grants from the Medical Research Council of Canada. B.S. is a research fellow of the Deutscher Akademischer Austauschdienst. R.D. is a scholar of the Fonds de la Recherche en Santé du Québec. We thank Drs. T. G. Sherman and R. C. Thompson for the AVP, OT, and CRH cDNA clones.

Correspondence should be addressed to Dr. Robert Day, J. A. DeSève Laboratory of Biochemical Neuroendocrinology, Clinical Research Institute of Montréal, 110 Pine Avenue West, Montréal, Québec, Canada H2W 1R7.

Copyright (C) 1997 Society for Neuroscience $0270-6474 / 97 / 170563-13 \$ 05.00 / 0$
(Seidah et al., 1992). PC1, PC2, and PC5 mRNAs mainly are expressed neuronally, whereas furin and PACE4 transcripts are in both neuronal and glial cells. PC7 is expressed widely in the CNS and can be demonstrated in both neuronal and non-neuronal cells. The principal aim of such mapping studies is to define potential functions and putative substrates for each $\mathrm{PC}$ but also to define whether PCs have distinct or redundant functions.

The hypothalamic paraventricular nucleus (PVN) and supraoptic nucleus (SON) are the hypothalamic origin of neurosecretory neurons for which multiple peptide hormones have been identified (Bondy et al., 1989), including corticotrophin-releasing hormone (CRH) (Krieger et al., 1977), vasopressin (AVP) (Vandesande et al., 1975), and oxytocin (OT) (Vandesande et al., 1975). PC1, PC2, and PC5 gene expression also have been detected in the PVN and SON (Schäfer et al., 1993; Dong et al., 1995), suggesting their involvement in the processing of pro-AVP, proOT, and pro-CRH. The PVN is subdivided into cell groups according to the size of the neuronal perikarya, their projections, and anatomic organization (Armstrong et al., 1980; Swanson and Kuypers, 1980). Mapping each PC within PVN subdivisions should reveal correlations with potential proneuropeptide substrates. As a central regulating organ of the neuroendocrine system, the synthesis and release of PVN peptide hormones are regulated by inputs from other brain regions (Herman et al., 1994) and by glucocorticoid feedback (Fink et al., 1991). It is, therefore, of interest to determine whether PC gene expression can be 


\section{PC1}
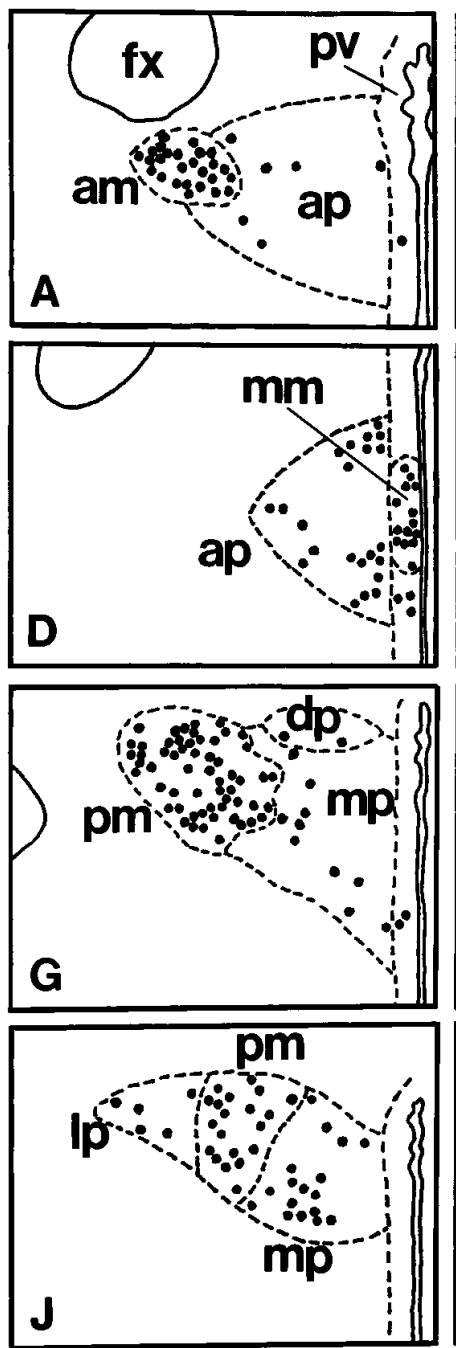

PC2
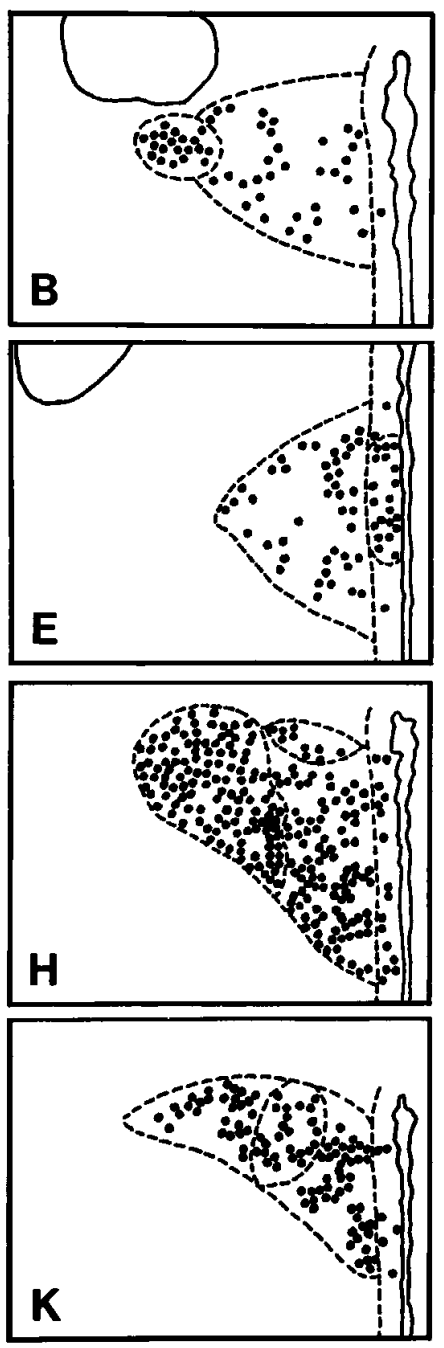

PC5
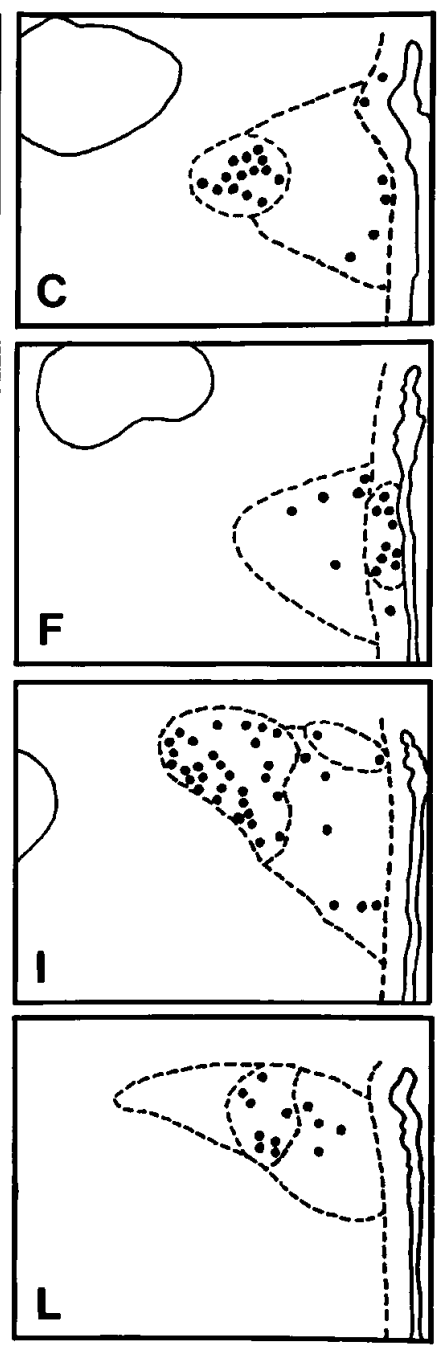

Figure 1. Line drawings from rostral to caudal orientation show the distribution of PC1 $(A, D, G, J), \mathrm{PC} 2(B, E, H, K)$, and PC5 $(C, F, I, L)$ mRNAs in the hypothalamic paraventricular nucleus. The black dots represent positively labeled cells. am, Anterior magnocellular; mm, medial magnocellular; $p m$, posterior magnocellular; $a p$, anterior parvocellular; $m p$, medial parvocellular; $d p$, dorsal parvocellular; $l p$, lateral parvocellular regions. $F x$, Fornix; $p v$, hypothalamic periventricular nucleus.

regulated under the same conditions. Changes in PC levels or activity could be an important mechanism in regulating biological output of neuroendocrine neurons. In the present study, we mapped PC mRNA expression in each PVN subdivision and colocalized each PC transcript with pro-AVP, pro-OT, and pro$\mathrm{CRH}$ mRNAs in both PVN and SON. We also investigated the effects of adrenalectomy (ADX) with or without corticosterone (CORT) or dexamethasone (DEX) replacement on PC gene expression in the PVN.

\section{MATERIALS AND METHODS}

Animals and tissue preparation. All animal experiments were conducted in accordance with the guidelines of the Medical Research Council of Canada and National Institutes of Health Guide for the Care and Use of Laboratory Animals. For the mapping and colocalization studies, eight male Sprague Dawley rats (200-250 gm) were used. For the ADX study, male Sprague Dawley rats $(250 \mathrm{gm})$ were divided into four groups of six rats each: group I, sham ADX and vehicle injection; group II, sham ADX and DEX or CORT treatment; group III, ADX and DEX or CORT treatment; group IV, ADX and vehicle injection. The ADX studies were repeated in two separate experiments. ADX or sham ADX was performed under methofane anesthesia. After $10 \mathrm{~d}$, three rats in each group received either subcutaneous injections of $500 \mu \mathrm{g} / \mathrm{kg}$ DEX (Sigma, St. Louis, MO) or vehicle injections twice a day for $4 \mathrm{~d}$. The other three rats in each group were injected subcutaneously with $40 \mathrm{mg} / \mathrm{kg}$ CORT (Research Biochemicals, Natick, MA) or vehicle injection once a day for $5 \mathrm{~d}$. Saline was given to all the animals as drinking water after the operation. Then the animals were decapitated and the brains were rapidly removed and frozen in isopentane precooled to $-35^{\circ} \mathrm{C}$. The brains were stored at $-80^{\circ} \mathrm{C}$ and later sectioned on a cryostat at a thickness of $10 \mu \mathrm{m}$. The coronal brain sections were thaw-mounted on slides coated with poly-Llysine and stored at $-80^{\circ} \mathrm{C}$ until further processing. For immunocytochemistry, the adult male Sprague Dawley rats (300 gm) were treated with colchicine, as previously described (Marcinkiewicz et al., 1985). Briefly, the animals were anesthetized with sodium pentobarbital (50 $\mathrm{mg} / \mathrm{kg}$ body weight $)$, and then colchicine $(100 \mu \mathrm{g} / 10 \mu \mathrm{l})$ was administered into the lateral ventricle. The coordinates were L-1.4 mm, H-7.0 mm, and A-7.3 mm, from the stereotaxic atlas of the rat brain (Paxinos and Watson, 1986). Forty-eight hours later the rats were reanesthetized and killed by cardiac perfusion with $0.9 \% \mathrm{NaCl}$ maintained at $37^{\circ} \mathrm{C}$, followed by a cold Bouin's solution. The whole brain was removed, minced, preserved in fixative for $12 \mathrm{hr}$ at $4^{\circ} \mathrm{C}$, dehydrated via a series of alcohols 

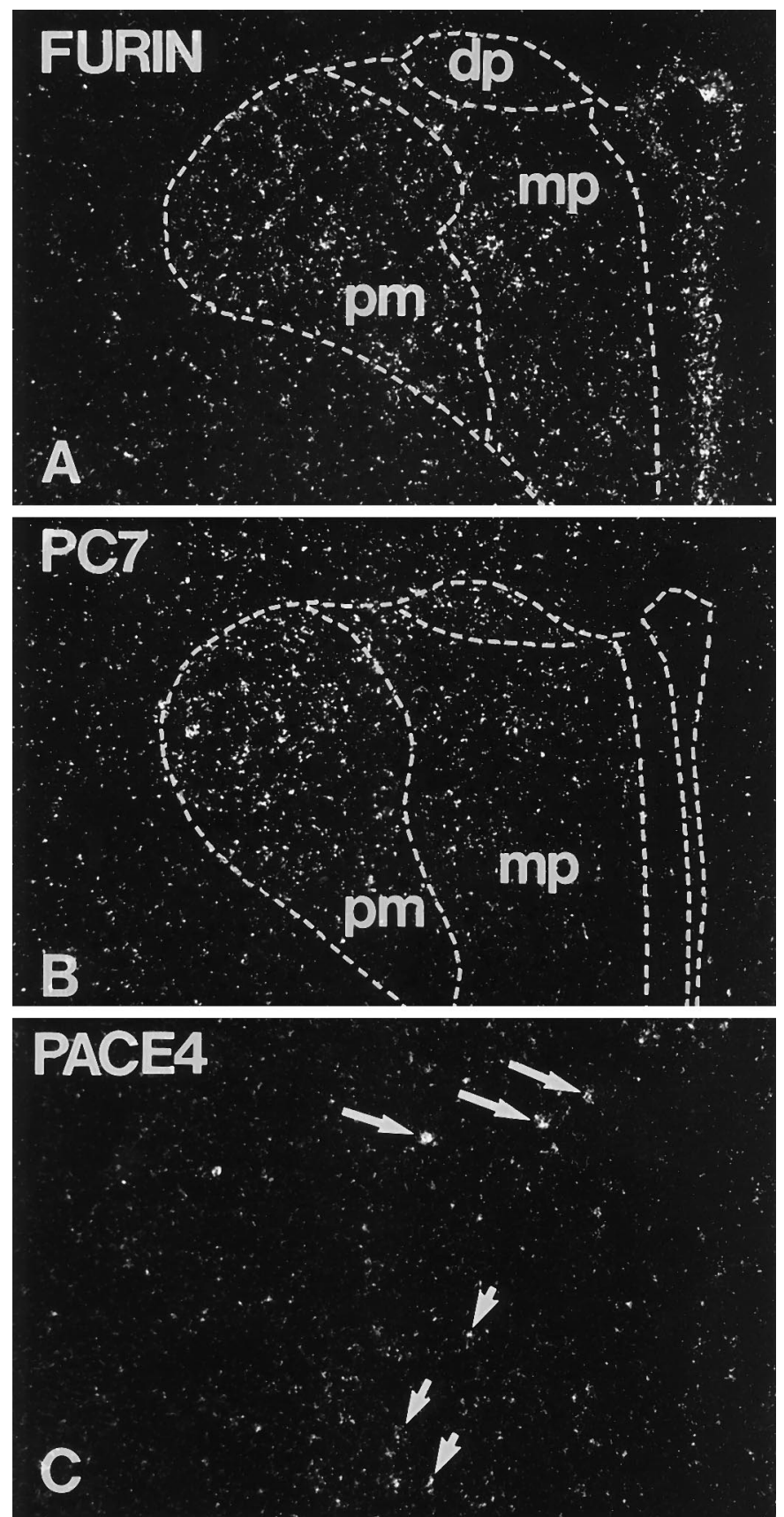

Figure 2. Dark-field images of in situ hybridization demonstrate furin, PC7, and PACE4 mRNAs distribution in the hypothalamic PVN. Furin and PC7 mRNAs are expressed in both magnocellular (pmPVN) and parvocellular (mpPVN), whereas PACE4 mRNA is detected only in a few scattered cells at this level (arrows). $d p$, Dorsal parvocellular region. Magnification is $100 \times$.

followed by xylene, embedded in paraffin, cut in $5 \mu \mathrm{m}$ sections, and mounted onto the microscopy slides.

Probe synthesis. $\left.{ }^{35} \mathrm{~S}\right] \mathrm{CTP}-$ and $\left[{ }^{35} \mathrm{~S}\right] \mathrm{UTP}-\mathrm{labeled}$ cRNA probes were prepared for $\mathrm{PC} 1, \mathrm{PC} 2, \mathrm{PACE} 4, \mathrm{PC} 5$, furin, and $\mathrm{PC} 7$ from cDNA subclones in transcription vectors. The rat (r) PC1 cDNA consisted of 590 nucleotides (nts) equivalent to segment 1841-2430 in mouse (m) PC1 (Seidah et al., 1991); rPC2 cDNA consisted of 425 nts equivalent to segment 1574-1998 in mPC2 (Seidah et al., 1990); rPACE4 cDNA consisted of 534 nts equivalent to the segment 1153-1687 of hPACE4 (Kiefer et al., 1991; Dong et al., 1995); rPC5 cDNA consisted of $837 \mathrm{nts,}$ segment 1089-1925 (Lusson et al., 1993; Dong et al., 1995); rfurin cDNA consisted of $1231 \mathrm{nts}$ equivalent to segment 823-2053 in human (h) furin
(Barr et al., 1991); and rPC7 cDNA consisted of 742 nts, segment 2170-2911 (Seidah et al., 1996). Probes were diluted in hybridization buffer to a final concentration of $33 \times 10^{3} \mathrm{dpm} / \mathrm{ml}$. Dithiothreitol was added to a final concentration of $20 \mathrm{~mm}$. Nonradioactive cRNA probes were prepared by using digoxigenin-11-UTP (Dig-UTP) for AVP, OT, and CRH as previously described (Schäfer and Day, 1994). The cDNA constructions for Dig-UTP-labeled probes were described previously for AVP and OT (Sherman et al., 1988) and for CRH (Herman et al., 1994).

In situ hybridization. The in situ hybridization protocols have been described in detail elsewhere (Schäfer and Day, 1994). The cRNA probes (either ${ }^{35} \mathrm{~S}$-labeled cRNA probes or a mixture of ${ }^{35} \mathrm{~S}$ - and Dig-labeled cRNA probes) were hybridized at $55^{\circ} \mathrm{C}$ for $16 \mathrm{hr}$. After RNase A treatment and high stringency washes, Dig was detected by using an anti-Dig antibody conjugated to alkaline phosphatase. Radioactivelabeled and radioactive/Dig-labeled slides were dipped in Ilford K-5D nuclear emulsion (Polysciences, Warrington, PA). All emulsion-dipped slides were stored at $4^{\circ} \mathrm{C}$ for $4-10$ weeks. Sections hybridized with radioactive cRNA probes alone were counterstained with cresyl violet, cleared in xylene, and mounted with Permount histological mounting medium (Fisher Scientific, Fair Lawn, NJ). Sections hybridized with both radioactive and Dig-labeled cRNA probes were mounted with MountQUICK aqueous mounting medium (Daido Sangyo, Japan). Observation and analysis were performed with a Zeiss Axiophot microscope equipped with a Darklite illuminator (Micro Video Instruments, Avon, MA). Colocalization photographs were taken with double-exposure settings. The autoradiographic grains were exposed first to technical Pan-negative film under dark light illumination, thus resulting in the white grain appearance. The second exposure shows the Dig-probe labeling revealed as dark immunocytochemical staining. Semiquantitative studies were performed at $400 \times$ magnification by counting the grains on Dig-labeled cells. Statistic results are expressed as mean \pm SEM. Comparison of mean values was performed by ANOVA, followed by the Tukey-Kramer multiple comparisons test. Differences were considered significant when $p$ was $<0.05$.

Western blot analysis. Total proteins were extracted from PVN, SON, and the complete pituitary, respectively, dissected from male Sprague Dawley rats (200-250 gm). Tissues were homogenized by means of glass microhomogenizers (Wheaton, Millvale, NJ) on ice in extraction buffer (50 mM Tris/Cl, pH 7.4, $2.5 \mathrm{~mm}$ EDTA, $150 \mathrm{~mm} \mathrm{NaCl}$, and $0.02 \%$ sodium azide) freshly supplemented with a protease inhibitor mix (final concentrations $100 \mu \mathrm{g} / \mathrm{ml}$ PMSF, $2 \mu \mathrm{g} / \mathrm{ml}$ leupeptin, $100 \mu \mathrm{M}$ pepstatin, $2 \mu \mathrm{g} / \mathrm{ml}$ aprotinin, and $2 \mathrm{~mm} \beta$-mercaptoethanol). After centrifugation at $14,000 \times g$ for $30 \mathrm{~min}$ at $4^{\circ} \mathrm{C}$, the supernatant was subjected to protein determination (Bradford, 1976), and $20 \mu \mathrm{g}$ of protein was applied on $7.5 \%$ SDS-polyacrylamide gels in minigel electrophoresis devices (BioRad, Richmond, CA). Then the separated proteins were electrotransferred onto Immobilon-P membranes (Millipore, Bedford, MA) and blocked with $1 \%$ blocking solution (BM chemiluminescent Western blotting kit, Boehringer Mannheim, Indianapolis, IN) in TBS (50 mM Tris and $150 \mathrm{~mm} \mathrm{NaCl}, \mathrm{pH} \mathrm{7.5)}$ for $1 \mathrm{hr}$ at room temperature. Blotted gels were Coomassie-stained to evaluate the efficiency of transfer and the equality of the protein amounts loaded.

The antibodies used were as follows: anti-PC1 and anti-PC2 antibodies raised in rabbits with the appropriate rat enzyme-GST fusion protein covering the $\mathrm{C}$ terminus (for PC1, amino acids 529-637 and for PC2, amino acids 529-637) (Benjannet et al., 1993). A rabbit anti-PC7 antiserum was raised against a multiple antigenic peptide (MAP) (amino acids 449-463, deduced from the protein sequence of rat PC7; Seidah et al., 1996). The PC5 antibody also was raised against a MAP peptide (amino acids 83-98; Lusson et al., 1993). Primary antibodies were diluted in $0.5 \%$ blocking solution 1:5000 (PC1), 1:13,000 (PC2), and 1:750 (PC7), and incubation was performed at $4^{\circ} \mathrm{C}$ overnight, followed by two washing steps in TBST (TBS containing $0.1 \%$ Tween 20 ) and two additional incubation steps in $0.5 \%$ blocking solution. The second antibody was an affinity-purified donkey anti-rabbit $\operatorname{Ig}(\mathrm{H}+\mathrm{L})$ peroxidase conjugate (Jackson ImmunoResearch, West Grove, PA), diluted 1:10,000 in $0.5 \%$ blocking solution. Polyvinylidene fluoride (PVDF) membranes were incubated with the diluted conjugate for $1 \mathrm{hr}$ at room temperature, washed four times in TBST for $15 \mathrm{~min}$ each, and processed for chemiluminescence with the Boehringer Mannheim chemiluminescent kit according to the manufacturer's instructions. As specificity controls, antisera were preabsorbed with the appropriate fusion proteins or peptide sequences, respectively. Immunocytochemical procedures were performed by the avidinbiotin complex method according to the manufacturer's procedure (Vector Laboratories, Burlingame, CA). 

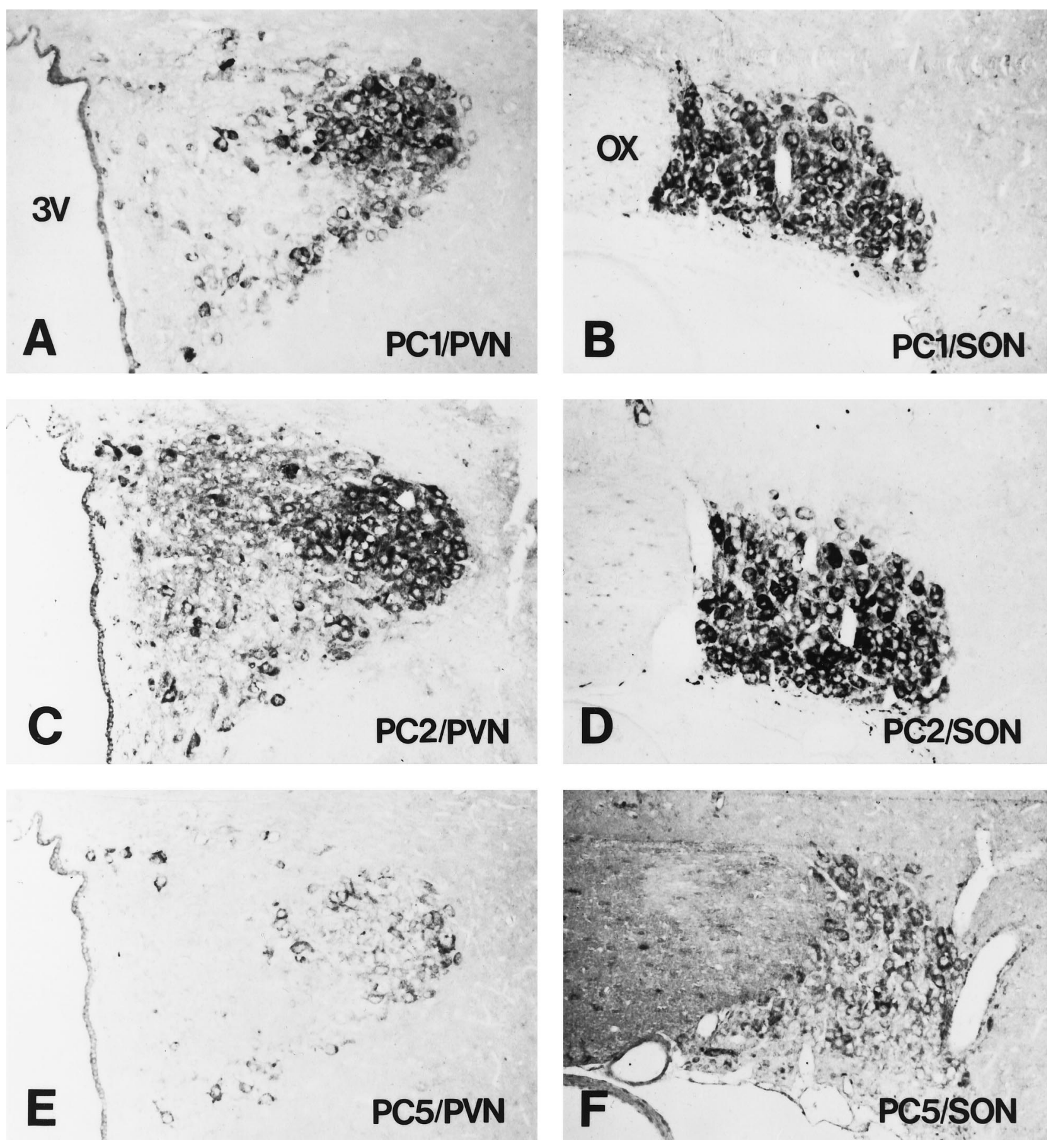

Figure 3. Immunohistochemistry shows $(A, B) \mathrm{PC} 1,(C, D) \mathrm{PC} 2,(E, F) \mathrm{PC} 5,(G, H)$ furin, and $(I, J) \mathrm{PC} 7$ immunoreactivity in the $\mathrm{PVN}$ and SON of colchicine-treated rats. PC1 and PC5 immunoreactivities are distributed mainly in the magnocellular neurons, whereas PC2 immunoreactivity is identified in both the magnocellular and parvocellular neurons. Furin immunoreactivity is observed mainly in the marginal region of pmPVN, whereas PC7 immunoreactivity is most intense in the central portion of the pmPVN. $K, L$, Example control sections showing blocking of PC2 immunoreactivity by preadsorption. $3 V$, Third ventricle; $O X$, optical chiasm. Magnification is $107 \times$. Figure 3 continues.

\section{RESULTS}

\section{PC mRNA distribution in PVN subnuclei}

The PVN is divided into seven subnuclei, including anterior magnocellular $(\mathrm{am})$, medial magnocellular $(\mathrm{mm})$, posterior magnocellular ( $\mathrm{pm}$ ), anterior parvocellular (ap), medial parvocellular (mp), dorsal parvocellular (dp), and lateral parvocellular (lp) regions (Swanson and Kuypers, 1980). Figure 1 shows the distribution of PC1, PC2, and PC5 mRNAs in the PVN in a rostral- to-caudal direction (top to bottom). The first appearance of labeling in the PVN region is within the amPVN where $\mathrm{PC} 1, \mathrm{PC} 2$, and PC5 mRNAs were detected (Fig. $1 A-C$, respectively). Between the amPVN and the third ventricle lies the apPVN, where many PC2-expressing neurons were observed but only a few scattered neurons expressing PC1 or PC5. Caudally (Fig. $1 D-F$ ), PC1, PC2, and PC5 transcripts were detected in a small group of neurons in the mmPVN, near the third ventricle. At this level, more PC1 

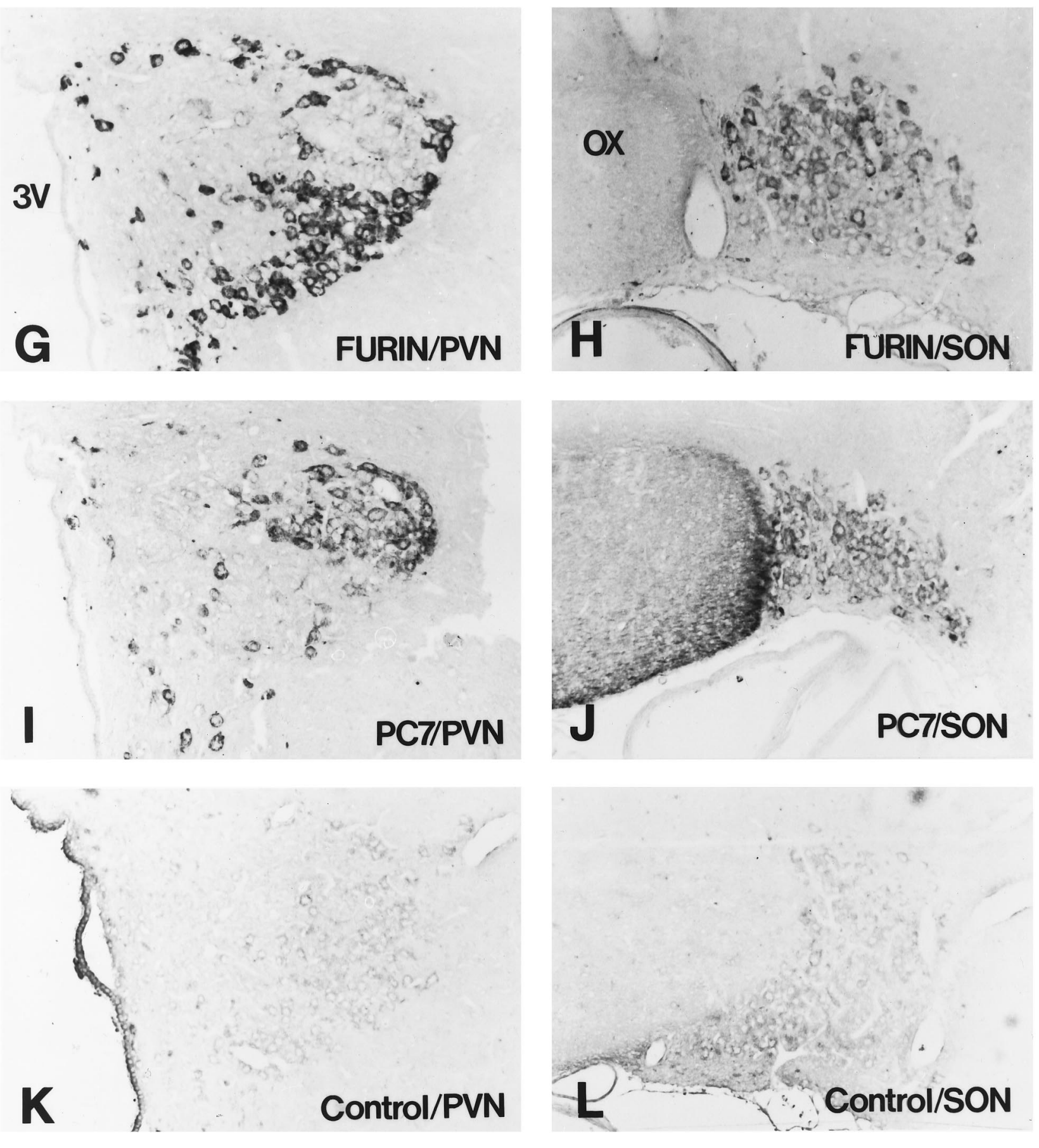

Figure 3 continued.

mRNA-positive neurons were found in the apPVN (Fig. 1D), as compared with a more rostral level (Fig. $1 A$ ). At the level shown in Figure $1 G-I, \mathrm{PC} 1 \mathrm{mRNA}$-positive neurons were observed more frequently in the central region of the pmPVN (Fig. 1G) (AVPlike distribution), whereas PC5 mRNA-positive cells were located at the margin surrounding the core of pmPVN (Fig. 1I) in a manner reminiscent of OT distribution (Sawchenko and Swanson, 1982). Also at this level (Fig. $1 H$ ), almost all PVN neurons expressed PC2 mRNA. In the dpPVN and mpPVN, only a few scattered cells expressed PC1 (Fig. $1 G$ ) or PC5 (Fig. 1I) mRNAs. Finally, at the most caudal levels (Fig. $1 J-L$ ), many neurons expressed PC2 mRNA in the pmPVN, lpPVN, and mpPVN (Fig. $1 K)$. PC1 mRNA-positive neurons were observed in the pmPVN and mpPVN with only a few scattered neurons in the lpPVN (Fig. $1 J$ ). Very few PC5-positive cells were observed at this level (Fig. $1 L$ ). The PVN distribution of PACE4 mRNA (Fig. 2C) was not mapped with the same level of detail, because it was very low to undetectable. Although furin mRNA has been shown to be ubiquitous, it was noted that PVN and SON expressed higher levels of furin transcripts than adjacent hypothalamic areas (Fig. 2A). Finally, PC7 mRNA was expressed throughout the PVN and SON in a similar distribution to that of furin (Fig. $2 B$ ). 


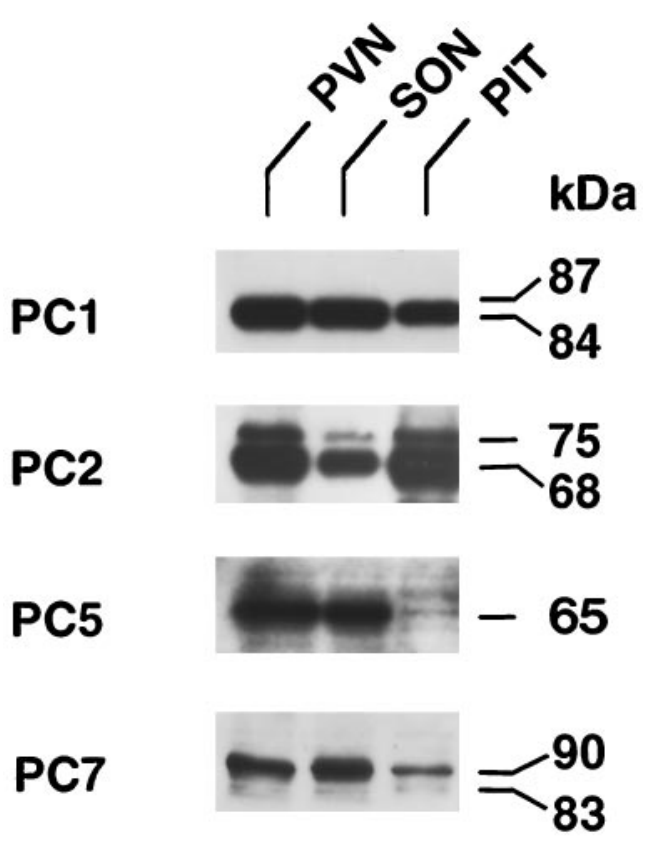

Figure 4. Western blot analysis illustrates the protein products of PC1, PC2, PC5, and PC7 in PVN, SON, and pituitary (PIT). For PC1, only the $84 \mathrm{kDa}$ mature peptide is identified, whereas for PC2, both the pro $(75$ $\mathrm{kDa})$ and mature forms $(68 \mathrm{kDa})$ are observed. For PC5 a major band is observed at $65 \mathrm{kDa}$, and for PC7 both a major $90 \mathrm{kDa}$ and a minor $83 \mathrm{kDa}$ band are evident. Each of these described bands is displaceable by preadsorption.

\section{Immunohistochemical distribution of PCs in the PVN and SON of hypothalamus}

To demonstrate that PC mRNAs are translated in the PVN and SON, we used immunohistochemistry to detect PC proteins (Fig. 3). To demonstrate PC localization within PVN and SON, we believed it was essential to block intracellular transport by colchicine treatment, which causes the disruption of neurotubule organization, thus preventing fast axonal transport (Alonso, 1988). PC1 (Fig. 3A,B) and PC5 (Fig. 3E-F) were both observed only in magnocellular PVN and SON neurons. $\mathrm{PC} 1$ detection was more intense in the central portion of the pmPVN (Fig. 3A), whereas PC5 was observed only in the marginal part of the pmPVN (Fig. $3 E$ ), distributions that are AVP- and OT-like, respectively. In contrast, PC2 immunoreactivity was observed in both magnocellular PVN and SON neurons (Fig. $3 C, D$ ) and also in parvocellular PVN neurons (Fig. 3C). Furin (Fig. 3G,H) and PC7 (Fig. 3I,J) also could be demonstrated in both PVN and SON neurons. The intensity of furin and PC7 neuronal localization contrasts with the more widespread distribution observed when examining furin and PC7 mRNAs (Fig. 2A,B). This effect may be attributable to the effectiveness of cholchicine in accumulating furin and PC7 within neurosecretory neurons, although not having much effect on adjacent non-neuronal cells also expressing these enzymes. It was noted that furin staining was highest (but not exclusive) in the marginal region of magnocellular PVN neurons with a pattern similar to that of OT neurons (Fig. $3 G$ ), whereas PC7 immunoreactivity was observed principally in the central regions of this nuclei in a pattern similar to that of AVP neurons (Fig. 3I).

\section{Western blot analysis}

We examined the protein forms of various PCs in dissected rat PVN and SON (Fig. 4). Pituitary tissues were used as a control. The aim of these studies was not only to establish that PC proteins were synthesized in these tissues but also to determine whether mature forms of these enzymes could be demonstrated. We demonstrated the presence of PC1, PC2, PC5, and PC7 by Western blot. Each of the demonstrated bands was displaced when the antisera were preincubated with the appropriate antigens. It was noted that only the mature form of PC1 $(84 \mathrm{kDa})$ was observed in either SON or PVN. However, as expected, a combination of pro-PC2 $(75 \mathrm{kDa})$ and mature $\mathrm{PC} 2(68 \mathrm{kDa})$ was observed in these same tissue extracts. It is well known that the activation of pro-PC2 to PC2 is a slower process (Benjannet et al., 1993) and that steady-state levels of pro-PC2 can be observed. The presence of the mature forms of PC1 $(84 \mathrm{kDa})$ and PC2 $(68 \mathrm{kDa})$ suggest that active enzyme is present in both the PVN and SON. Finally, we also observed a $65 \mathrm{kDa}$ PC5 and a $90 \mathrm{kDa}$ PC7 form in SON and PVN. The observed $65 \mathrm{kDa}$ form of PC5 represents a mature processed form of PC5, which is C-terminal-truncated and has been shown to be associated with cells that have a regulated secretory pathway (DeBie et al., 1996). The observed band at 90 $\mathrm{kDa}$ correlates well with the predicted size of a mature PC7 protein (Seidah et al., 1996), suggesting that this could be the active form of PC7. Interestingly, a lower band of weaker intensity $(83 \mathrm{kDa})$ also was observed. This smaller form (also displaced by antigen preadsorption) could represent a processed form of PC7.

\section{Coexpression of PCs with AVP, OT, and CRH in normal rats}

Using Dig-labeled cRNA probes, we detected OT (Fig. 5) and AVP (Fig. 6) mRNAs in PVN and SON magnocellular neurons, whereas CRH mRNA was demonstrated in PVN parvocellular neurons (Fig. 7, see darkly stained cells in each panel). PC1, PC2, and PC5 were detected simultaneously in each tissue section by radioactively labeled cRNA probes (i.e., revealed white grains in each panel). In Figure 5, the analysis was performed for OT cells and demonstrated that PVN and SON pro-OT-expressing magnocellular neurons also expressed PC1 (Fig. 5A,B), PC2 (Fig. $5 B, C$ ), and PC5 (Fig. 5E,F) mRNAs. In Figure 6, the analysis was performed for AVP cells and demonstrated that PVN and SON pro-AVP-expressing magnocellular neurons expressed PC1 (Fig. $6 A, B$ ) and PC2 (Fig. $6 C, D$ ), but very little PC5 (Fig. 6E,F). Finally, in Figure 7, the same analysis was done for CRH parvocellular PVN neurons. Very little PC1 mRNA could be demonstrated in pro-CRH mRNA-expressing cells (Fig. 7A). Note the high levels of $\mathrm{PC} 1$ (white grains) in non-CRH-expressing neurons. However, all pro-CRH mRNA-expressing neurons also contained PC2 mRNA (Fig. 7B). PC5 mRNA could not be detected in any pro-CRH mRNA-positive neurons (Fig. $7 C$ ). After examining detailed analysis of over 300 sections, we summarized the data for Table 1. This Table also includes the data obtained for furin, PACE4, and PC7. Under basal conditions PC1 mRNA levels were higher in AVP neurons than OT neurons and were very low in parvocellular CRH neurons (Table 1). In contrast, PC2 was highly expressed in all three cells types (AVP, OT, and CRH neurons), whereas PC5 mRNA was expressed mainly in OT neurons. There was no significant difference among the levels of PC2 mRNA in the three cell populations. Furin and PC7 mRNA were detected throughout the PVN and SON, although PACE4 mRNA was undetectable (except for occasional scattered cells). 

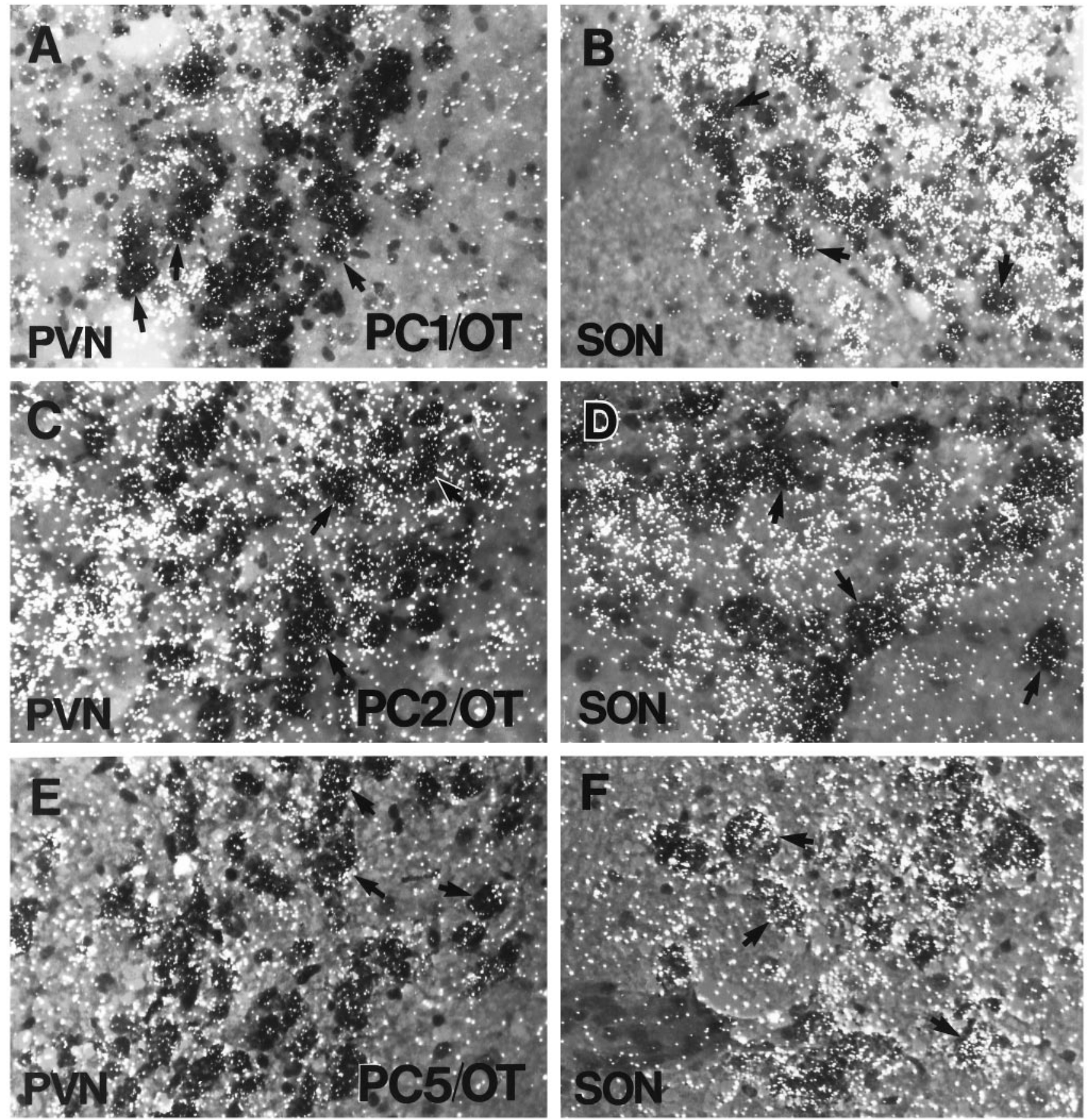

Figure 5. Double-labeled in situ hybridization of $(A, B) \mathrm{PC} 1,(C, D) \mathrm{PC} 2$, and $(E, F)$ PC5 mRNAs with OT. The labeled OT mRNA is revealed as darkly stained neurons, and labeled PC mRNA is observed as white grains. PC1 mRNA was colocalized with OT mRNA (arrows) either in PVN or in SON; however, the expression levels (grain numbers) are low, as compared with non-OT-positive cells (i.e., neurons labeled only with white grains). PC2 mRNA also was colocalized with OT mRNA-expressing neurons (arrows). No significant difference of PC2 expression levels (grain numbers) can be seen between the OT-positive neurons and OT-negative neurons. PC5 mRNA was colocalized with OT neurons (arrows) but is low in non-OT neurons. Magnification: $A, C, E, 270 \times ; B, 215 \times ; D, 306 \times ; F, 300 \times$

\section{Effects of ADX and glucocorticoids on PC gene expression in the PVN}

After ADX, we observed a significant induction of PC1 mRNA in mpPVN neurons, with no change in PC1 mRNA within pmPVN neurons (Fig. $8 A, B$ ). To establish the precise neurons involved in this effect, we repeated the study using our dual-labeling in situ hybridization methodology. In these experiments, tissue sections were hybridized simultaneously with PC1/AVP (Fig. 8C,D) or
PC1/CRH (Fig. 8E,F) cRNA probes. Pro-AVP and pro-CRH mRNA-expressing neurons are observed as darkly staining cells, whereas PC1 mRNA is observed as white grains. As expected, after ADX, AVP mRNA levels are induced in the mpPVN (Fig. $8 C, D$ ) (Young et al., 1986). In these same mpPVN neurons, PC1 mRNA is always detected after ADX (Fig. $8 D$ ). In the case of CRH, mRNA expression is highly upregulated after ADX (Fig. $8 E, F)$, and PC1 mRNA is always detected with pro-CRH mRNA 

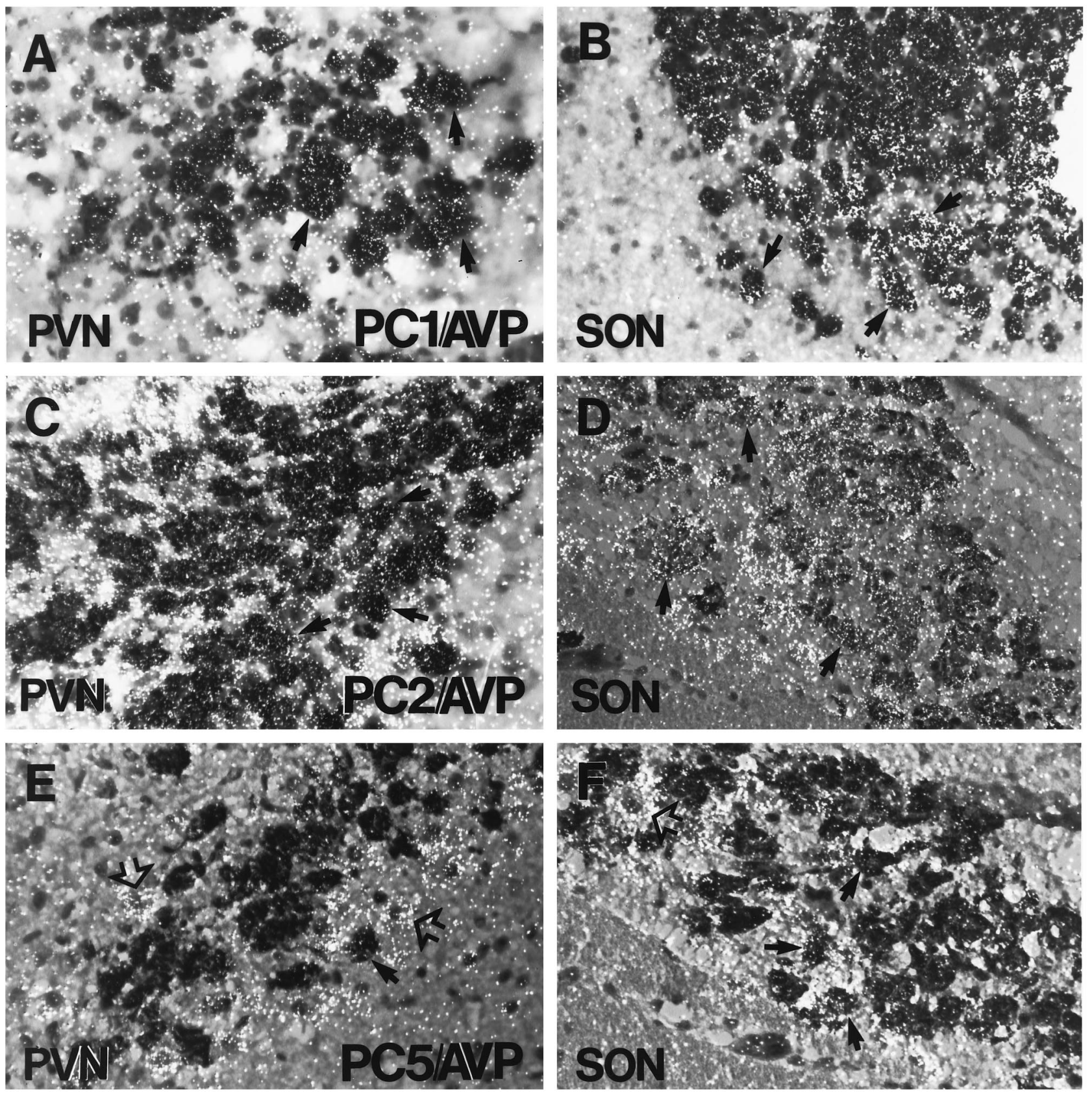

Figure 6. Colocalization of convertase $(A, B) \mathrm{PC} 1,(C, D) \mathrm{PC}$, and $(E, F)$ PC5 mRNAs with AVP mRNA, using double-labeled in situ hybridization. PC1 and PC2 mRNAs are colocalized with AVP (solid arrows). PC5 mRNA in AVP-expressing neurons is either low or undetectable. Open arrows show examples for which PC5 mRNA is not colocalized with AVP mRNA. Magnification: $A, C, E, 280 \times ; B, 215 \times ; D, 240 \times ; F, 320 \times$.

after ADX (Fig. $8 F$ ). With the knowledge that AVP and CRH are colocalized in the mpPVN after ADX treatment (Sawchenko et al., 1984; Wolfson et al., 1986), it now seems that PC1 also is highly expressed in these same neurons when glucocorticoids are removed. Administration of DEX or CORT to ADX animals completely reversed the effects of ADX, because PC1 mRNA could no longer be detected in the mpPVN. As for the other PCs, no changes were detected for either PC2, PC5, furin, or PACE4 mRNAs after ADX or glucocorticoid treatment.

Figure 9 shows a semiquantitative analysis of PC1 mRNA (as indicated by the number of grains/neuron) in all four groups examined, i.e., sham, ADX, sham/DEX, and ADX/DEX. PC1 mRNA was determined in (1) parvocellular pro-CRH mRNA- positive neurons, (2) magnocellular pro-AVP-positive neurons, and (3) magnocellular pro-OT-positive neurons. Within pro-CRH expressing neurons, PC1 mRNA levels were increased fourfold after ADX treatment, as compared with sham-operated rats. DEX treatment completely reversed this effect. No effects were observed for PC1 mRNA in AVP or OT magnocellular neurons.

\section{DISCUSSION}

The hypothalamic PVN and SON have a central role in the control of a number of important physiological functions, including the regulation of stress, osmotic balance, appetite, and reproductive function. Some important mediators of these functions are the numerous neuropeptides that are biosynthesized in the dis- 

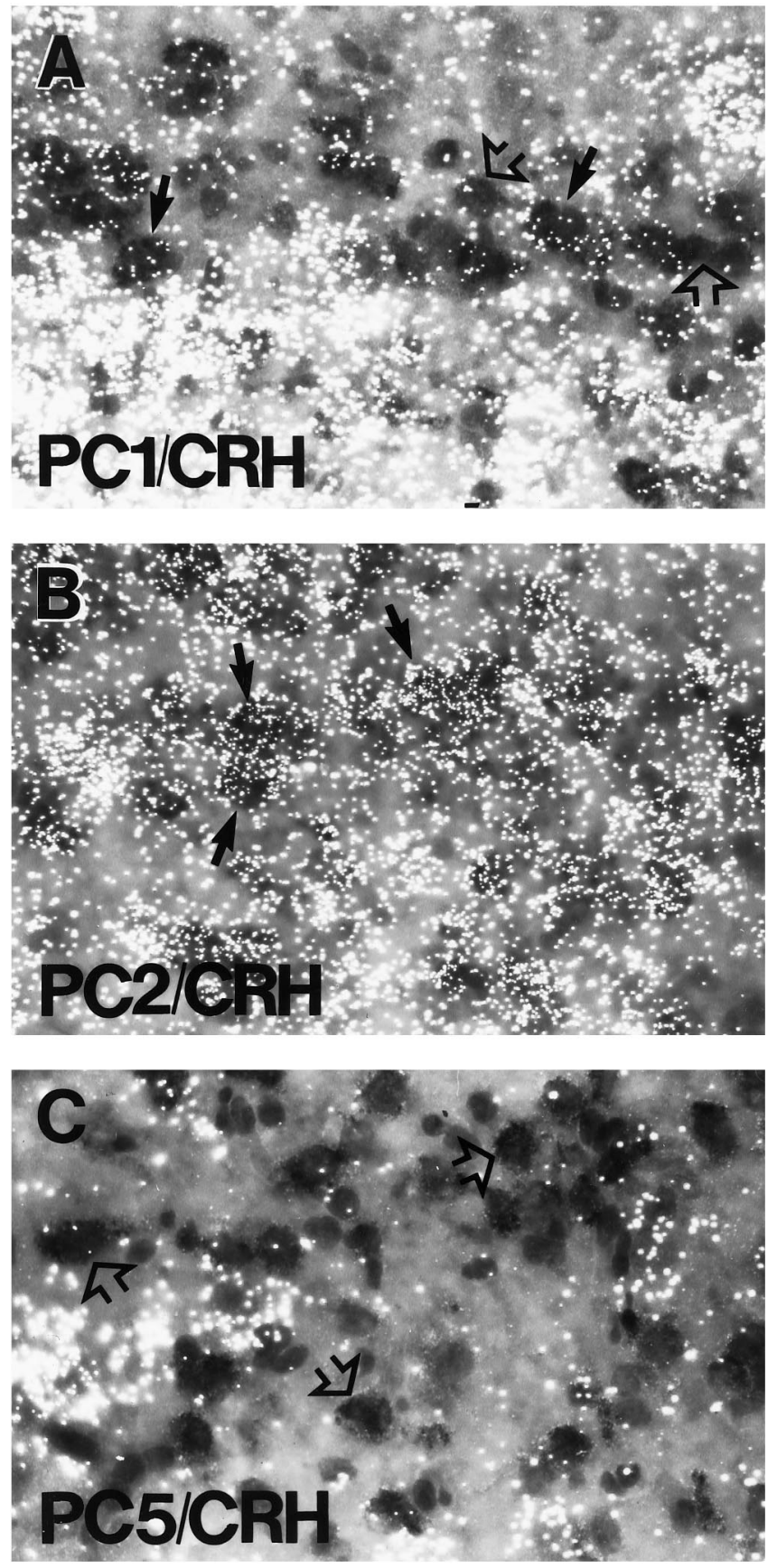

Figure 7. Colocalization of $(A) \mathrm{PC} 1,(B) \mathrm{PC}$, and $(C)$ PC5 mRNAs with CRH mRNA in the PVN. In CRH-expressing cells, PC1 mRNA levels are either very low (solid arrows) or undetectable (open arrows). Similar expression levels of PC2 mRNA are observed in both CRH cells (solid arrows) and non-CRH cells. PC5 mRNA is undetectable in CRH geneexpressing cells (open arrows). Magnification, $440 \times$.

tinct cell types of the SON and PVN, including AVP, OT, and $\mathrm{CRH}$. The PCs are excellent candidate enzymes to perform the activation of these neuropeptides on the basis of their previously characterized cleavage specificity and localization in the hypothalamus. However, the PCs now comprise a family of seven enzymes in mammalian species, and it is not clear which PC or PCs are responsible for the activation of each of the neuropeptide precursors in the PVN and SON. Both nuclei are composed of heterogeneous neuronal populations, but, although the cellular distribu- tion of many neuropeptides has been mapped carefully, information on the cellular expression of each convertase is lacking. Although convertases have the general function of cleaving at basic residues, each enzyme has different cleavage specificities, which do allow us to predict which enzymes will be involved in the activation of a particular precursor. Furthermore, an observed cleavage, whether demonstrated by using a cellular expression system (e.g., cotransfection of PC and precursor) or an in vitro assay (e.g., co-incubation of substrate and purified PC), will not have relevance to the physiological context, unless the enzyme and substrate are colocalized in vivo (Docherty and Steiner, 1982). Thus, the primary goal of the present study is to map carefully, at a cellular level, the distribution of each PC in the SON and PVN, with a special emphasis on three distinct groups of neurons: those producing AVP, OT, and CRH. The present data suggest distinct roles for each convertase but also provide a basis for the study of the processing of other neuropeptides known to be expressed in the SON and PVN.

Using double-labeling in situ hybridization, we demonstrated the coexpression of PC1 and PC2 mRNAs in PVN and SON AVP and OT neurons. However, only PC2 mRNA was localized in $\mathrm{CRH}$ neurons, whereas PC1 mRNA levels were low to undetectable. Interestingly, PC5 mRNA was expressed selectively in OT neurons, but not in AVP or CRH neurons, suggesting a specific role of PC5 either in the processing of pro-OT or in the processing of other proproteins specifically expressed in OT neurons of the PVN and SON. Taken together, these data suggest that pro-AVP may be processed by PC1 and/or PC2, pro-OT could be processed by $\mathrm{PC} 1, \mathrm{PC} 2$, and/or PC5, whereas pro-CRH could be processed only by PC2 (i.e., under basal conditions).

Regarding the distribution of the other convertases, furin and PACE4, our study has less emphasized these particular distributions for the following reasons. In the case of furin, we observed that this gene is expressed by all cells examined, as previously reported (Day et al., 1993), although PVN and SON neurons express higher levels of this mRNA than in other hypothalamic areas. Therefore, under the colocalization criteria stated in the above discussion, furin always could be considered as a candidate processing enzyme. However, our study did not address the issue of intracellular compartmental colocalization. A convertase and a substrate could be colocalized but never meet within the secretory pathway because of differential sorting mechanisms. In the case of furin, it has been shown that this convertase resides in the TGN and will process precursor proteins negotiating the constitutive pathways of secretion, whereas AVP, CRH, and OT are all known to be stored in secretory granules. Therefore, although colocalized with pro-AVP, pro-OT, and pro-CRH, furin remains an unlikely in vivo candidate processing enzyme for these precursors. The case of PACE4 in the PVN and SON is simpler, because we could not observe any expression in either nuclei, as previously shown (Dong et al., 1995). Therefore, as with PC4, which is not expressed in the brain (i.e., exclusively expressed in testicular germ cells), we conclude that PACE4 and PC4 are not involved in the processing of precursors in the PVN and SON. PACE4 mRNA has been detected in other hypothalamic regions, such as the arcuate nucleus (Dong et al., 1995), and could have a role to play in the processing of other proneuropeptides, such as POMC, because PACE4 and POMC mRNA were colocalized in some arcuate neurons (our unpublished data). As for PC7, it also remains as a potential candidate processing enzyme, because we could demonstrate both mRNA and protein expression in the PVN. Because very little is known about the substrate specificity of this novel 
Table 1. Summary of colocalization distribution data of PC mRNAs in the PVN and SON

\begin{tabular}{|c|c|c|c|c|c|c|c|}
\hline & & $\mathrm{PC} 1$ & PC2 & FURIN & PACE4 & PC5 & PC7 \\
\hline \multirow[t]{3}{*}{ PVN } & AVP & +++++ & +++++ & ++ & - & \pm & ++ \\
\hline & OT & +++ & +++++ & ++ & - & ++++ & ++ \\
\hline & $\mathrm{CRH}$ & \pm & +++++ & ++ & - & - & ++ \\
\hline \multirow[t]{2}{*}{ SON } & AVP & +++++ & +++++ & ++ & - & \pm & ++ \\
\hline & OT & +++ & +++++ & ++ & - & ++++ & ++ \\
\hline
\end{tabular}

PC4 is expressed only in germ cells; thus, it is not examined in the present study.
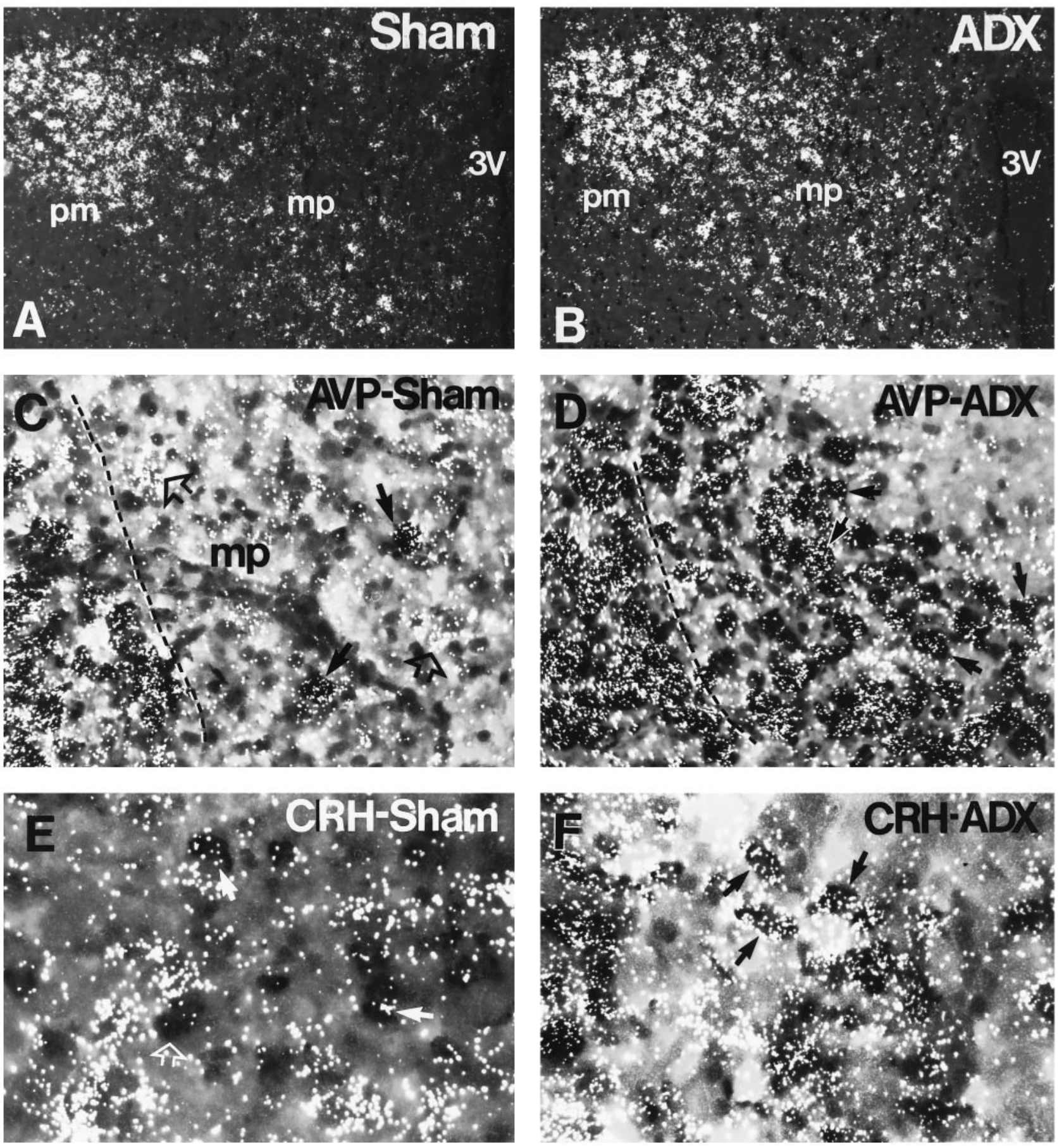


\section{PC1 Gene Expression in the PVN of Hypothalamus}
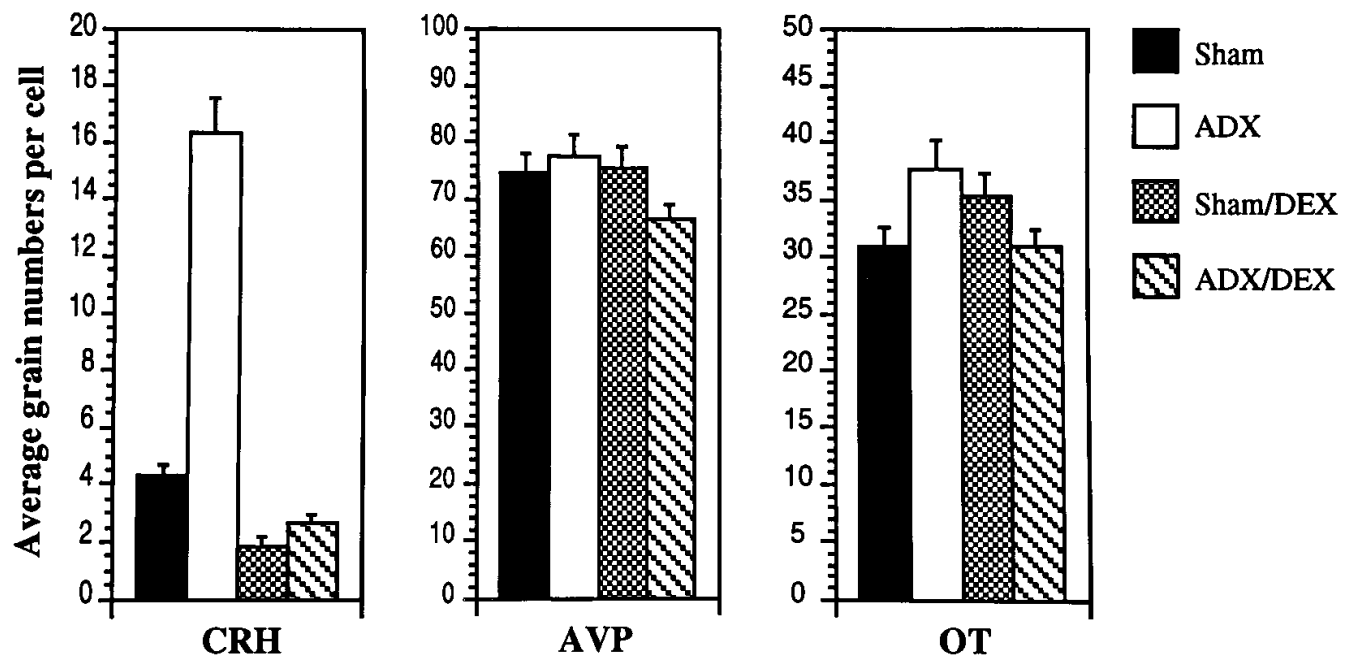

Figure 9. Semiquantitative analysis of PC1 mRNA in PVN of ADX-treated rats. For AVP- and OT-expressing cells, grain counting was done in the pmPVN. A fourfold increase of PC1 mRNA levels was observed in the CRH-expressing cells after adrenalectomy $(p<0.001)$. No significant difference in PC1 mRNA levels was found in AVP or OT cells. Each bar represents grain counting in $n=60-90$ neurons. For each bar, the neurons counted are from a minimum of nine brain sections from three different rats.

enzyme, any opinion about its role in the PVN remains speculative.

Our results differ from a previous preliminary study that examined the distribution of PC1 and PC2 in the PVN and SON (Birch et al., 1994). Using a combined immunohistochemistry and in situ hybridization histochemistry approach, Birch et al. (1994) colocalized PC1 and PC2 only within SON and PVN AVP neurons but failed to detect either PC1 or PC2 in OT neurons. The authors concluded that PC1 and PC2 were unlikely candidates in pro-OT processing. Our present results are in strong disagreement with this conclusion, because we easily could demonstrate both PC1 and PC2 coexpression in OT cells. Therefore, PC1 and/or PC2 could be responsible for the processing of pro-OT. In addition, the amino acid cleavage site to generate OT is a typical Type II site (Seidah, 1995), which is compatible with either PC1 or PC2 substrate specificity (i.e., PLGGKR $\downarrow$ AA). However, PC5 can also be considered as a candidate convertase for pro-OT, because PC5 mRNA was localized exclusively in OT cells. We conclude that the differences observed between our study and that of Birch et al. (1994) are attributable to the different methodologies used.

Previous studies have shown that PC expression levels could be up- or downregulated under various conditions (Bloomquist et al., 1991; Day et al., 1992). Therefore, it is very likely that manipulations of the hypothalamic-pituitary-adrenal (HPA) axis could result in changes in PC expression levels in the PVN. In the present study, we demonstrated that PC1 mRNA levels also were upregulated, and this effect could be blocked by administration of CORT or DEX. On the other hand, no significant change of PC1 mRNA levels was observed in the magnocellular PVN neurons.
The observed effect in the parvocellular PVN was selective for PC1 mRNA, because none of the other convertases was changed. Under such conditions, PC1 may have a role to play in the processing of pro-CRH. Alternatively, if $\mathrm{PC} 1$ does not play a role in pro-CRH processing, it is noted that the increased PC1 levels are concomitant to the known increased levels of pro-AVP mRNA in these parvocellular neurons. Thus, the significance of increased PC1 mRNA levels in PVN parvocellular neurons could be important for the processing of pro-AVP. This hypothesis can be tested by examining the processing of pro-AVP and pro-CRH by PC1. Alternatively, changes of the expression levels of other peptides in PVN, such as galanin, also were reported with ADX (Hedlund et al., 1994), and PC1 also could play a role in the processing of such precursors.

The up- or downregulation of PC gene expression has been observed in various tissues and under different conditions (Day et al., 1992; Johnson et al., 1994; Mania-Farnell et al., 1996); the significance of these changes is not clearly understood but has led to the suggestion that changes in PC1 and PC2 gene expression may be useful as indicators of peptidergic activity (Birch et al., 1994). Our present data suggest that such determinations would be inadequate, because only PC1 was regulated by removal of glucocorticoids and not PC2. The present data are also consistent with data showing that PC1 and PC2 are differentially expressed and regulated (Day et al., 1992; Mania-Farnell et al., 1996). It is more likely that the differential expression of PC1 and PC2 serves as a mechanism of regulating the final cellular biological output, often observed as tissue-specific processing.

In conclusion, we have mapped, at a cellular level, the localiza-

$\leftarrow$

Figure 8. A comparison of PC1 mRNA expression levels in PVN between sham-treated rats (Sham) and adrenalectomized rats (ADX). $A$, Dark-field image of sham-treated animal shows that only scattered cells were labeled in the mpPVN and that, in $B$ the same region of ADX rats, PC1 mRNA levels were increased. This increase was confirmed further by using double-labeled in situ hybridization when PC1 mRNA was colocalized with AVP mRNA in the parvocellular region from sham-treated $(C$, solid and open arrows $)$ and $\mathrm{ADX}(D$, solid arrows $)$ rats. Also shown is a comparison of PC1 mRNA levels in CRH gene-expressing neurons from sham-treated $(E)$ and ADX $(F)$ animals. Solid arrows indicate CRH neurons expressing PC1 mRNA, whereas open arrows indicate $\mathrm{CRH}$ neurons without expression of PC1 mRNA. Magnification: $A, B, 108 \times ; C, D, 290 \times ; E, F, 400 \times$. 
tion of each convertase in AVP, OT, and CRH neurons. These neurons express different "sets" of PCs both under basal and regulated conditions. These data will permit the rationalization of further investigations into the substrate specificity of each convertase for precursors expressed in these neurons. The induction of PC1 expression in PVN parvocellular neurons, after ADX, further reinforces the notion that the expression of certain $\mathrm{PC}$ genes has a high degree of plasticity (Day et al., 1992, 1995; Scopsi et al., 1995; Mania-Farnell et al., 1996). The mechanism of action explaining these observations lies in understanding the transcriptional machinery of these convertases at a molecular level, which, to date, is poorly studied. Finally, the cellular output of biologically active neuropeptides (and other factors) is the result of differential precursor processing and plasticity of PC cellular expression, both of which are closely connected.

\section{REFERENCES}

Alonso G (1988) Effects of colchicine on the intraneuronal transport of secretory material prior to the axon: a morphofunctional study in hypothalamic neurosecretory neurons of the rat. Brain Res 453:191-203.

Armstrong WE, Waeach S, Hatton GI, McNell TH (1980) Subnuclei in the rat hypothalamic paraventricular nucleus: a cytoarchitectural, horseradish peroxidase, and immunocytochemical analysis. Neuroscience 5:1931-1958.

Barr PJ, Mason OB, Landsberg KE, Wong PA, Kiefer MC, Brake AJ (1991) cDNA and gene structure for a human subtilisin-like protease with cleavage specificity for paired basic amino acid residues. DNA Cell Biol 10:319-328.

Benjannet S, Rondeau N, Paquet L, Boudreault A, Lazure C, Chrétien M, Seidah NG (1993) Comparative biosynthesis, covalent posttranslational modifications, and efficiency of prosegment cleavage of the prohormone convertases PC1 and PC2: glycosylation, sulphation, and identification of the intracellular site of prosegment cleavage of PC1 and PC2. Biochem J 294:735-743.

Birch NP, Nakes DJ, Dixon JE, Mezey E (1994) Distribution and regulation of the candidate prohormone processing enzymes SPC2 and SPC3 in adult rat brain. Neuropeptides 27:307-322.

Bloomquist BT, Eipper BA, Mains RE (1991) Prohormone-converting enzymes: regulation and evaluation of function using antisense RNA. Mol Endocrinol 5:2014-2024.

Bondy CA, Whinall MH, Brady LS, Gainer H (1989) Coexisting peptides in hypothalamic neuroendocrine systems: some functional implications. Cell Mol Neurobiol 9:427-446.

Bradford MM (1976) A rapid and sensitive method for the quantitation of microgram quantities of protein utilizing the principle of protein-dye binding. Anal Biochem 72:238-254.

Bruzzaniti A, Goodge K, Jay P, Taviaux SA, Lam MHC, Berta P, Martin TH, Moseley JM, Gillespie MT (1996) PC8, a new member of the convertase family. Biochem J 314:727-731.

Day R, Schäfer MK-H, Watson SJ, Chrétien M, Seidah NG (1992) Distribution and regulation of the prohormone convertases PC1 and PC2 in the rat pituitary. Mol Endocrinol 6:485-497.

Day R, Schäfer MK-H, Watson SJ, Chrétien M, Seidah NG (1993) Region-specific expression of furin mRNA in the rat brain. Neurosci Lett 149:27-30.

Day R, Benjannet S, Matsuuchi L, Kelly R, Marcinkiewicz M, Chrétien M, Seidah NG (1995) Maintained expression of the prohormone convertases PC1 and PC2 in variant AtT-20 cell lacking a regulated secretory pathway. DNA Cell Biol 14:175-188.

DeBie I, Marcinkiewicz M, Malide D, Lazure C, Nakayama K, Bendayan M, Seidah NG (1996) The isoforms of the proprotein convertase PC5 are sorted to different subcellular compartments. J Cell Biol, in press.

Docherty K, Steiner DF (1982) Post-translational proteolysis in polypeptide hormone biosynthesis. Annu Rev Physiol 44:625-638.

Dong W, Marcinkiewicz M, Vieau D, Chrétien M, Seidah NG, Day R (1995) Distinct mRNA expression of the highly homologous convertases PC5 and PACE4 in the rat brian and pituitary. J Neurosci 15:1778-1796.

Fink G, Rosie R, Sheward WJ, Thomson E, Wilson H (1991) Steroid control of central neuronal interactions and function. J Steroid Biochem Mol Biol 48:123-132.
Hedlund PB, Koenig JI, Fuxe K (1994) Adrenalectomy alters discrete galanin mRNA levels in the hypothalamus and mesencephalon of the rat. Neurosci Lett 170:77-82.

Herman JP, Cullinan WE, Watson SJ (1994) Involvement of the bed nucleus of the stria terminalis in tonic regulation of paraventricular hypothalamic CRH and AVP mRNA expression. J Neuroendocrinol 6:433-442.

Johnson RC, Darlington DN, Hand TA, Bloomquist BT, Mains RE (1994) PACE4, a subtilisin-like endoprotease prevalent in the anterior pituitary and regulated by thyroid status. Endocrinology 135:1178-1185.

Kiefer MC, Tucker JE, Joh R, Landsberg KE, Saltman D, Barr PJ (1991) Identification of a second human subtilisin-like protease gene in the fes/fps region of chromosome 15. DNA Cell Biol 10:757-769.

Krieger DT, Liotta A, Brownstein MJ (1977) Corticotropin releasing factor distribution in normal and Brattleboro rat brain, and effect of deafferentation, hypophysectomy, and steroid treatment in normal animals. Endocrinology 100:227-237.

Lusson J, Vieau D, Hamelin J, Day R, Chrétien M, Seidah NG (1993) cDNA structure of the mouse and rat subtilisin/kexin-like PC5: a candidate proprotein convertase expressed in endocrine and nonendocrine cells. Proc Natl Acad Sci USA 90:6691-6695.

Mania-Farnell BL, Botros I, Day R, Davis TP (1996) Differential modulation of prohormone convertase mRNA by second messenger activators in two cholecystokinin-producing cell lines. Peptides 17:47-54.

Marcinkiewicz M, Benjannet S, Cantin M, Seidah NG, Chrétien M (1985) CNS distribution of a novel pituitary protein 7B2 localization in secretory and synaptic vesicles. Brain Res 380:349-356.

Meerabux J, Yaspo ML, Roebroek AJ, Van de Ven WJM, Lister A, Young BD (1996) A new member of the proprotein convertase gene family (LPC) is located at a chromosome translocation breakpoint in lymphomas. Cancer Res 56:448-456.

Nakagawa T, Hosaka M, Torii S, Watanabe T, Murakami K, Nakayama K (1993) Identification and functional expression of a new member of the mammalian Kex2-like processing endoprotease family: its striking structural similarity to PACE4. J Biochem 113:132-135.

Nakayama K, Kim WS, Torii S, Hosaka M, Nakagawa T, Ikumizu J, Baba T, Murukami K (1992) Identification of the fourth member of the mammalian endoprotease family homologous to the yeast Kex2 protease. J Biol Chem 267:5897-5900.

Paxinos G, Watson C (1986) The rat brain in stereotaxic coordinates. San Diego: Academic.

Roebroek AJM, Schalken JA, Leunissen JAM, Onnekink C, Gloemers HPJ, Van de Van WJM (1986) Evolutionary conserved close linkage of c-fes/fps proto-oncogene and genetic sequences encoding a receptorlike protein. EMBO J 5:2197-2202.

Sawchenko PE, Swanson LW (1982) Immunohistochemical identification of neurons in the paraventricular nucleus of the hypothalamus that project to the medulla or to the spinal cord in the rat. J Comp Neurol 205:260-272.

Sawchenko PE, Swanson LW, Vale WW (1984) Coexpression of corticotropin-releasing factor and vasopressin immunoreactivity in parvocellular neurosecretory neurons of the adrenalectomized rat. Proc Natl Acad Sci USA 81:1883-1887.

Schäfer MK-H, Day R, Cullinan WE, Chrétien M, Seidah NG, Watson SJ (1993) Gene expression of prohormone and proprotein convertases in the rat CNS: a comparative in situ hybridization analysis. J Neurosci 13:1258-1279.

Schäfer MK-H, Day R (1994) In situ hybridization techniques to study processing enzyme expression at the cellular level. Methods Neurosci 23:16-44.

Scopsi L, Gullo M, Rilke F, Martin S, Steiner DF (1995) Proprotein convertases (PC1/PC3 and PC2) in normal and neoplastic human tissues: their use as markers of neuroendocrine differentiation. J Clin Endocrinol Metab 80:294-301.

Seidah NG (1995) The mammalian family of subtilisin/kexin-like proprotein convertases. In: Intramolecular chaperones and protein folding (Shinde U, Inouye M, eds), pp 181-203. Austin, TX: Landes.

Seidah NG, Gaspar L, Mion P, Marcinkiewicz M, Mbikay M, Chrétien M (1990) cDNA sequence of two distinct pituitary proteins homologous to Kex2 and furin gene products: tissue-specific mRNAs encoding candidates for prohormone processing proteinases. DNA Cell Biol 9:415-424.

Seidah NG, Marcinkiewicz M, Benjannet S, Gaspar L, Beaubien G, Mattei MG, Lazure C, Mbikay M, Chrétien M (1991) Cloning and primary sequence of a mouse candidate prohormone convertase PC1 homolo- 
gous to PC2, furin, and Kex2: distinct chromosomal localization and messenger RNA distribution in brain and pituitary compared to PC2. Mol Endocrinol 5:111-122.

Seidah NG, Day R, Hamelin J, Gaspar A, Collard MW, Chrétien M (1992) Testicular expression of PC4 in the rat: molecular diversity of a novel germ cell-specific Kex2/subtilisin-like proprotein convertase. Mol Endocrinol 6:1559-1569.

Seidah NG, Hamelin J, Mamabrachi M, Dong W, Tadros H, Mbikay M, Chrétien M, Day R (1996) cDNA structure, tissue distribution, and chromosomal localization of rat PC7, a novel mammalian proprotein convertase closest to yeast kexin-like proteinases. Proc Natl Acad Sci USA 93:3388-3393.

Sherman TG, Day R, Civelli O, Douglass J, Herbert E, Akil H, Watson SJ (1988) Regulation of hypothalamic magnocellular neuropeptides and their mRNAs in the Brattleboro rat: coordinate responses to further osmotic challenge. J Neurosci 8:3785-3796.

Smeekens SP, Steiner DF (1990) Identification of a human insulinoma cDNA encoding a novel mammalian protein structurally related to the yeast dibasic processing protease Kex2. J Biol Chem 265:2997-3000.

Smeekens SP, Avruch AS, LaMendola J, Chan SJ, Steiner DF (1991) Identification of a cDNA encoding a second putative prohormone convertase related to PC2 in AtT-20 cells and islets of Langerhans. Proc Natl Acad Sci USA 88:340-344.

Swanson LW, Kuypers HGJM (1980) The paraventricular nucleus of the hypothalamus: cytoarchitectonic subdivisions and organization of projections to the pituitary, dorsal vagal complex, and spinal cord as demonstrated by retrograde fluorescence double-labeling methods. J Comp Neurol 194:555-570.

Vandesande F, Diericks K (1975) Identification of the vasopressinproducing and of the oxytocin-producing neurons in the hypothalamic magnocellular neurosecretory system of the rat. Cell Tissue Res 164:153-162.

Van de Ven WJM, Voorberg J, Fontijn R, Pannekoek H, van den Ouweland AMW, van Duijnhoven HLP, Roebroek AJM, Siezen RJ (1990) Furin is a subtilisin-like proprotein processing enzyme in higher eukaryotes. Mol Biol Rep 14:265-275.

Wolfson B, Manning RW, Davis LG, Arentzen R, Baldino F (1986) Colocalization of corticotropin releasing factor and vasopressin mRNA in neurons after adrenalectomy. Nature 315:59-61.

Young WS, Mezey E, Siegel RE (1986) Vasopressin and oxytocin mRNAs in adrenalectomized and Brattleboro rats: analysis by quantitative in situ hybridization histochemistry. Brain Res 387:231-241. 